\title{
MODIFICAÇÃo ENZIMÁTICA DA FARINHA DE ARROZ VISANDO A PRODUÇÃO DE AMIDO RESISTENTE
}

\author{
Márcio Garcia Severo, Kelly de Moraes* e Walter Augusto Ruiz \\ Escola de Química e Alimentos, Universidade Federal do Rio Grande, CP 474, 96201-900 Rio Grande - RS, Brasil
}

Recebido em 8/3/09; aceito em 12/8/09; publicado na web em 11/1/10

\begin{abstract}
ENZYMATIC MODIFICATION ON RICE FLOUR SEEKING THE PRODUCTION OF RESITANT STARCH. The aim of this work was to study the enzymatic modification on rice flour using lipase pancreatic and amyloglucosidase to obtain resistant starch. For this, Response Surface Methodology (RSM) was used to determine the best operating conditions for each enzyme. For lypase pancreatic, the highest value for resistant starch (45\%) was achieved within $2 \mathrm{~h}$ reaction at $\mathrm{pH} 7 \mathrm{using}$ an enzyme/substrate ratio of $4 \%$ (w/w) and $\mathrm{Dp}=100 / 200$ tyler. For amyloglucosidase, optima conditions corresponded to an enzyme/substrate ratio of $0,006 \mathrm{~mL} / \mathrm{g}$ and $\mathrm{Dp}=$ $100 / 200$ tyler at $45{ }^{\circ} \mathrm{C}$, yielding $57 \%$ of resistant starch in $2 \mathrm{~h}$ reaction. These results show the potential of using both enzymes to modified rice flour, increasing the resistant starch in about 5.7 folds in relation to the flour without treatment (resistant starch=10.6\%).
\end{abstract}

Keywords: amyloglucosidase; modifying native starches; debranching.

\section{INTRODUÇÃOO}

O interesse do consumidor em alimentos específicos que possuam um papel na manutenção da saúde tem crescido nos últimos anos. Os chamados "alimentos funcionais" referem-se a estes gêneros alimentícios, os quais podem proporcionar benefícios nutricionais, dietéticos e metabólicos específicos, e contribuir para o controle e a redução do risco de doenças. ${ }^{1,2} \mathrm{O}$ arroz (Oryza sativa, L.) é uma das principais fontes de calorias e proteínas na alimentação de mais da metade da população mundial. Entre os cereais, apresenta maior digestibilidade, maior valor biológico e a mais elevada taxa de eficiência proteica. ${ }^{3}$

O Brasil, no ano de 2008, alcançou uma produção de arroz de aproximadamente 12,1 milhões de toneladas. Para que o arroz seja aceito pelo consumidor, torna-se necessário seu processamento, o que resulta em alguns subprodutos como a casca, o farelo e grão quebrados, que correspondem a $14-15 \%$ do total, o que representa um valor superior 1,8 milhões de toneladas. Estes grãos são utilizados em grande parte para alimentação animal e na produção da farinha de arroz. ${ }^{4,5}$

Na farinha de arroz, os carboidratos são representados basicamente pelo amido, que é formado por cadeias de amilose e amilopectina, responsáveis por muitas das propriedades do produto final. O segundo componente em maior quantidade na estrutura da farinha de arroz é a proteína, respondendo por cerca de 7-9\% da sua composição. Segundo a legislação brasileira, a farinha de arroz pode ser denominada e vendida como amido de arroz, em função do seu alto teor de amido e a dificuldade de se extrair as proteínas. ${ }^{5}$

Atualmente, vem crescendo o interesse dos pesquisadores em quantificar estas frações do amido nos alimentos, visando avaliar o seu real consumo e correlacionar estes achados com a nutrição e a saúde dos

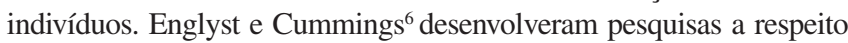
das frações do amido, assim como suas classificações e propriedades. $\mathrm{O}$ amido é classificado em função da sua estrutura físico-química e da sua susceptibilidade à hidrólise enzimática. As frações do amido dividem-se, de acordo com a velocidade com a qual o alimento é digerido in vitro, em: rapidamente digerível (ARD), quando, ao ser submetido à incubação com amilase pancreática e amiloglicosidase em uma temperatura de 37 ${ }^{\circ} \mathrm{C}$, se converte em glicose em $20 \mathrm{~min}$; lentamente digerível (ALD), se, nas condições anteriores, é convertido em glicose em 120 min; e amido resistente (AR), que resiste à ação das enzimas digestivas. .,6-8 $^{2}$

*e-mail: kellyengalimentos@gmail.com
A fração do amido que não é digerida no intestino delgado, mas que posteriormente é fermentada no intestino grosso é denominada, em termos fisiológicos, de amido resistente (AR), que pode ser comparado a uma fibra dietética total (de acordo com a legislação, Resolução RDC 40/2001 - ANVS/MS). ${ }^{2,9}$ Por ser um alimento fermentado no intestino grosso, principalmente pelas bifidobactérias, o amido resistente é considerado um agente prebiótico, pois contribui para a saúde do cólon, devido à produção de ácidos graxos de cadeia curta (AGCC), e também auxilia no controle do diabetes. ${ }^{2,3,7}$ A farinha de arroz possui na sua composição cerca de $90 \%$ em amido mostrando, assim, uma grande abundância deste componente e a possibilidade de ser utilizada como amido modificado, agregando valor ao produto. Porém, no Brasil, não se tem conhecimento de tecnologia para extração do amido de arroz em escala industrial.

Desta forma, o conhecimento do potencial de utilização do amido da farinha do arroz, como amido modificado, sem a necessidade da etapa de extração, tornaria possível seu aproveitamento na elaboração de produtos diferenciados, mais específicos e muito interessantes do ponto de vista econômico para as indústrias de beneficiamento de arroz. O método mais utilizado e que foi precursor no estudo dos amidos modificados é a hidrólise ácida, seguida da modificação física dos amidos. Embora a modificação ácida ainda seja muito utilizada, esta vem perdendo espaço para as modificações enzimáticas, que apresentam muitas vantagens, entre as quais a especificidade das enzimas, que proporciona a obtenção de produtos com propriedades químicas e físicas mais bem definidas. Outra vantagem é que a reação mais branda resulta em menos reações secundárias e menos escurecimento dos produtos finais..$^{5,10}$

A formação de amido resistente depende de muitos fatores como $\mathrm{pH}$, temperatura, tempo de reação, tempo de estocagem, número de ciclos de aquecimento e resfriamento, tipo de amido e conteúdo de água. ${ }^{11,12}$ Alguns estudos vêm comprovando a possibilidade de alteração das frações de amido rapidamente digerível (ARD), amido lentamente digerível (ALD) e amido resistente (AR) através de modificações estruturais de amidos nativos.

Tendo em vista o que foi exposto, este trabalho teve como objetivo estudar a influência da proporção enzima/substrato (E/S), tempo, diâmetro de partícula (Dp), $\mathrm{pH}$ e temperatura da modificação enzimática da farinha de arroz, utilizando as enzimas lipase pancreática e amiloglicosidase na produção de amido resistente, determinando-se a melhor região de trabalho por meio de análise de superfície de resposta. 


\section{PARTE EXPERIMENTAL}

Os experimentos foram efetuados com a lipase pancreática adquirida da Sigma-Aldrich Chemical Co. (St. Louis, MO, EUA), com atividade específica de $0,098 \mathrm{mg}$ tirosina $\mathrm{g}^{-1}$ proteína $\mathrm{min}^{-1} \mathrm{e}$ amiloglicosidase AMG-300L (Novozymes), grau alimentício, produzida por linhagem selecionada de Aspergillus niger gentilmente doada pela Novozymes (Araucária, PR), com as seguintes propriedades: $\mathrm{AE}=300 \mathrm{AGU} / \mathrm{mL}$, $\mathrm{pH}$ ótimo entre 4 a 4,5 e temperatura entre 58 a $70{ }^{\circ} \mathrm{C}$.

Todos os experimentos foram efetuados com farinha de arroz comercializada sob a designação de Amitec 100 (A-100) e gentilmente doada por uma indústria de processamento da cidade de Pelotas-RS.

A farinha de arroz foi classificada por meio de um conjunto de peneiras entre 24/48 e 100/200 mesh, com vibração por 30 min, para separação de frações com diferentes diâmetros de partículas, com retenção de $10 \%$ da massa total em mesh $24 / 48$ e $68 \%$ da massa total em mesh 100/200.

As amostras foram acondicionadas sob refrigeração $\left(-18{ }^{\circ} \mathrm{C}\right)$ até sua utilização. Todos os outros reagentes empregados foram de grau analítico.

\section{Delineamento experimental}

Para cada enzima testada foi realizado um estudo do efeito das variáveis de acordo com um delineamento fatorial misto $\left(2^{3} \times 3\right)$, constituído de 24 experimentos, em duplicata. As variáveis e níveis selecionados para cada delineamento fatorial estão dispostos na Tabela 1 .

Tabela 1. Variáveis e níveis estudados no processo de modificação enzimática

\begin{tabular}{lccccc}
\hline Enzima & Fatores & Variáveis & \multicolumn{3}{c}{ Níveis } \\
\hline \multirow{4}{*}{ Lipase pancreática } & & & -1 & 0 & 1 \\
& $X_{1}$ & $\mathrm{E} / \mathrm{S}(\%)$ & 2 & 4 & 6 \\
& $X_{2}$ & Tempo(h) & 2 & - & 5 \\
& $X_{3}$ & $\mathrm{pH}$ & 5,9 & - & 7 \\
& $X_{4}$ & $\mathrm{Dp}(\mathrm{Tyler})$ & $24 / 48$ & & $100 / 200$ \\
& $X_{1}$ & $\mathrm{E} / \mathrm{S}(\mathrm{mL} / \mathrm{g})$ & 0,006 & 0,015 & 0,024 \\
Amiloglicosidase & $X_{2}$ & $\mathrm{~T}\left({ }^{\circ} \mathrm{C}\right)$ & 35 & - & 45 \\
& $X_{3}$ & Tempo (h) & 2 & - & 5 \\
& $X_{4}$ & Dp (Tyler)* & $24 / 48$ & - & $100 / 200$ \\
\hline
\end{tabular}

T=temperatura; *diâmetro de abertura: tyler fração passante/fração retida - 24/48 corresponde a $0,707 / 0,297 \mathrm{~mm}\left(\mathrm{Dp}_{\text {médio }}=0,502 \mathrm{~mm}\right)$; tyler $100 / 200$ corresponde a $0,149 / 0,074 \mathrm{~mm}\left(\mathrm{Dp}_{\mathrm{m} e ́ d i o}=0,111 \mathrm{~mm}\right)$.

Para os experimentos efetuados com a lipase pancreática foram consideradas como variáveis independentes: relação enzima/substrato $(\mathrm{E} / \mathrm{S})$, tempo de hidrólise, $\mathrm{pH}$ e diâmetro da partícula (Dp), mantendo-se fixa a temperatura de $37^{\circ} \mathrm{C}$. Para a amiloglicosidase foram consideradas como variáveis: relação enzima/substrato (E/S), temperatura, tempo de hidrólise e diâmetro da partícula (Dp), mantendo-se fixo o $\mathrm{pH}$ em 5,9. Os valores de $\mathrm{pH}$ dos meios de hidrólise foram ajustados com solução $0,1 \mathrm{M}$ de $\mathrm{NaOH}$. As hidrólises foram realizadas em biorreatores encamisados de capacidade de $500 \mathrm{~mL}$, com temperatura controlada e agitação constante (200 rpm). Em cada experimento utilizaram-se $100 \mathrm{~g}$ de farinha de arroz numa relação sólido/líquido (S/L) de 1:2, variando-se as outras condições como descrito na Tabela 1. As enzimas foram diluídas previamente em água deionizada e utilizadas nas concentrações propostas nos planejamentos experimentais.
Os experimentos foram efetuados de maneira randômica. Ao final de cada experimento, a farinha modificada foi separada por centrifugação (3000 x g por $20 \mathrm{~min}$ ), em seguida desidratada em estufa com circulação de ar $\left(60{ }^{\circ} \mathrm{C}, 60 \mathrm{~min} / 105^{\circ} \mathrm{C}, 15 \mathrm{~min}\right)$ e posteriormente peneirada, separando-se a farinha com Tyler menor que $100(0,149$ $\mathrm{mm}$ de abertura) para a determinação da digestibilidade. Para ambos planejamentos fatoriais foi considerada como variável resposta a porcentagem de amido resistente (AR\%).

A análise estatística dos resultados foi realizada, com base na literatura, ${ }^{13,14}$ utilizando-se o programa Statistica 5.0 da Statsoft Inc. Corporate (Tulsa, OK, EUA). Modelos polinomiais foram ajustados por regressão não linear pelo método dos mínimos quadrados aplicados aos resultados experimentais obtidos no planejamento fatorial misto, como representado na Equação 1.

$Y i=b_{0}+\sum_{i=1}^{n} b i X i+\sum_{i=1}^{n} b i i X i i+\sum_{i=1}^{n} \sum_{j=i+j}^{n} b i j X i X j+\sum_{i=1}^{n} \sum_{j=i+j}^{n} b i j X i i X j$

em que Yi representa a variável resposta; $b_{0}, b_{i}, b_{i i}, b_{i j}$ representam os coeficientes da regressão e $\mathrm{X}_{\mathrm{i}}, \mathrm{X}_{\mathrm{j}}$, representam as variáveis estudadas.

\section{Métodos de análises}

Composição centesimal da farinha de arroz

$\mathrm{Na}$ farinha de arroz crua (A-100) foram determinadas umidade, proteína e cinzas segundo metodologias descritas pela AOAC. ${ }^{15} \mathrm{O}$ conteúdo de lipídios totais foi determinado segundo Bligh e Dyer. ${ }^{16}$ Os carboidratos totais foram medidos por diferença. O teor de amilose foi determinado utilizando o procedimento descrito por Sowbhagya e Bhattacharya,${ }^{17}$ que consiste na extração de amilose que reage com iodo e quantificação em espectrofotômetro a $630 \mathrm{~nm}$. O conteúdo de amilose foi calculado com base em uma curva padrão de amilose.

\section{Massa específica aparente da farinha de arroz}

A massa específica aparente ( $\left.\rho_{\text {aparente }}\right)$ foi determinada pela relação massa e volume de uma quantidade de amostra conhecida, medida através de um ensaio de proveta. Foi tomado o cuidado para que as amostras tivessem a mesma sedimentação. ${ }^{5}$

\section{Digestibilidade in vitro}

A digestibilidade in vitro das amostras de farinha de arroz modificada foi determinada segundo método de Englyst et al.$^{18}$ e modificado por Woo e Seib. ${ }^{19}$ Erlenmeyer de $125 \mathrm{~mL}$ contendo amostras de farinha de arroz modificada (200 mg), tampão acetato de sódio $(15 \mathrm{~mL}$ a pH 5,2 ) e solução enzimática composta de amiloglicosidade e lipase pancreática $(5 \mathrm{~mL})$ foram incubados em shaker a $(90$ ciclos $/ \mathrm{min})$ a $37^{\circ} \mathrm{C}$. Após $20 \mathrm{~min}$, uma alíquota $(0,5 \mathrm{~mL})$ foi retirada e adicionada a etanol 66\% (20 mL), misturado e centrifugado (3000 x g por $15 \mathrm{~min})$.

A concentração de glicose no sobrenadante foi determinada por glicose oxidase e o valor de amido rapidamente digerível (ARD) foi calculado multiplicando-se a glicose (mg) por 0,9 (fator de conversão de glicose para amido), dividindo pela massa de amostra $(200 \mathrm{mg})$ e multiplicando por $100 \%$. A concentração de glicose da digestão em 120 min foi determinada da mesma maneira, e o amido lentamente digerível (ALD) foi obtido pela diferença entre a digestão em 20 e 120 min. $\mathrm{O}$ amido resistente (AR) foi calculado pela diferença entre o total da amostra menos a soma do ARD e ALD.

\section{RESULTADOS E DISCUSSÃO}

\section{Composição centesimal da farinha de arroz}

A Tabela 2 apresenta a composição centesimal média e o conteúdo de amilose médio da farinha de arroz crua utilizada neste trabalho 
Tabela 2. Composição centesimal e conteúdo de amilose para farinha de arroz crua

\begin{tabular}{|c|c|c|c|c|c|c|}
\hline Amostra & $\begin{array}{l}\text { Umidade } \\
\qquad \%)\end{array}$ & $\begin{array}{c}\text { Carboidratos } \\
(\%)\end{array}$ & $\begin{array}{l}\text { Proteínas } \\
\qquad \%)\end{array}$ & $\begin{array}{l}\text { Lipídios totais } \\
(\%)\end{array}$ & $\begin{array}{c}\text { Cinzas } \\
(\%)\end{array}$ & $\begin{array}{c}\text { Amilose } \\
(\%)\end{array}$ \\
\hline Farinha de arroz crua** & 10,54 & 80,38 & 7,74 & 0,60 & 0,69 & 22,32 \\
\hline Farinha de arroz referência*** & 12,05 & 78,79 & 7,77 & 0,71 & 0,59 & 19,40 \\
\hline
\end{tabular}

*Medidos por diferença; ${ }^{* *}$ média de 3 repetições; ${ }^{* * *}$ dados referentes à farinha de arroz branca apresentados por King e Tan ${ }^{17}$

Tabela 3. Matriz do planejamento experimental misto $2^{3}$ x 3 para lipase pancreática e amiloglicosidase e resultados obtidos da fração de AR da farinha de arroz modificada enzimaticamente e não modificada

\begin{tabular}{|c|c|c|c|c|c|c|c|c|c|c|}
\hline \multirow[b]{2}{*}{ Exp. } & \multicolumn{6}{|c|}{ Lipase pancreática } & \multicolumn{4}{|c|}{ Amiloglicosidase } \\
\hline & $\begin{array}{c}\mathrm{E} / \mathrm{S} \\
\mathrm{X}_{1} \\
\end{array}$ & $\begin{array}{c}\text { Tempo } \\
\mathrm{X}_{2} \\
\end{array}$ & $\begin{array}{l}\mathrm{pH} \\
\mathrm{X}_{3} \\
\end{array}$ & $\begin{array}{l}\mathrm{Dp} \\
\mathrm{X}_{4} \\
\end{array}$ & $\begin{array}{l}\text { AR } \\
(\%) \\
\end{array}$ & $\begin{array}{c}\mathrm{E} / \mathrm{S} \\
\mathrm{X}_{1} \\
\end{array}$ & $\begin{array}{r}\mathrm{T} \\
\mathrm{X}_{2} \\
\end{array}$ & $\begin{array}{c}\text { Tempo } \\
\mathrm{X}_{3} \\
\end{array}$ & $\begin{array}{l}\mathrm{Dp} \\
\mathrm{X}_{4} \\
\end{array}$ & $\begin{array}{l}\mathrm{AR} \\
(\%)\end{array}$ \\
\hline 1 & -1 & -1 & -1 & -1 & $22,96 \pm 0,12$ & -1 & -1 & -1 & -1 & $21,13 \pm 0,65$ \\
\hline 2 & -1 & -1 & -1 & +1 & $24,53 \pm 0,18$ & -1 & -1 & -1 & +1 & $25,00 \pm 0,19$ \\
\hline 3 & -1 & -1 & +1 & -1 & $16,85 \pm 0,11$ & -1 & -1 & +1 & -1 & $19,75 \pm 0,52$ \\
\hline 4 & -1 & -1 & +1 & +1 & $33,57 \pm 0,07$ & -1 & -1 & +1 & +1 & $23,77 \pm 0,29$ \\
\hline 5 & -1 & +1 & -1 & -1 & $18,88 \pm 0,53$ & -1 & +1 & -1 & -1 & $43,05 \pm 0,10$ \\
\hline 6 & -1 & +1 & -1 & +1 & $43,29 \pm 0,05$ & -1 & +1 & -1 & +1 & $54,23 \pm 0,21$ \\
\hline 7 & -1 & +1 & +1 & -1 & $16,80 \pm 0,18$ & -1 & +1 & +1 & -1 & $46,23 \pm 0,42$ \\
\hline 8 & -1 & +1 & +1 & +1 & $45,50 \pm 0,16$ & -1 & +1 & +1 & +1 & $54,90 \pm 0,28$ \\
\hline 9 & 0 & -1 & -1 & -1 & $39,88 \pm 0,15$ & 0 & -1 & -1 & -1 & $21,76 \pm 0,19$ \\
\hline 10 & 0 & -1 & -1 & +1 & $37,23 \pm 0,55$ & 0 & -1 & -1 & +1 & $15,48 \pm 0,35$ \\
\hline 11 & 0 & -1 & +1 & -1 & $23,05 \pm 0,58$ & 0 & -1 & +1 & -1 & $27,69 \pm 0,24$ \\
\hline 12 & 0 & -1 & +1 & +1 & $46,35 \pm 0,6^{*}$ & 0 & -1 & +1 & +1 & $16,22 \pm 0,28$ \\
\hline 13 & 0 & +1 & -1 & -1 & $26,99 \pm 0,23$ & 0 & +1 & -1 & -1 & $54,46 \pm 0,10$ \\
\hline 14 & 0 & +1 & -1 & +1 & $27,80 \pm 0,48$ & 0 & +1 & -1 & +1 & $57,02 \pm 0,4$ \\
\hline 15 & 0 & +1 & +1 & -1 & $22,15 \pm 0,21$ & 0 & +1 & +1 & -1 & $52,50 \pm 0,49$ \\
\hline 16 & 0 & +1 & +1 & +1 & $28,23 \pm 0,32$ & 0 & +1 & +1 & +1 & $53,30 \pm 0,39$ \\
\hline 17 & +1 & -1 & -1 & -1 & $26,51 \pm 0,12$ & +1 & -1 & -1 & -1 & $12,65 \pm 0,22$ \\
\hline 18 & +1 & -1 & -1 & +1 & $30,66 \pm 0,30$ & +1 & -1 & -1 & +1 & $12,76 \pm 0,19$ \\
\hline 19 & +1 & -1 & +1 & -1 & $26,06 \pm 0,33$ & +1 & -1 & +1 & -1 & $14,49 \pm 0,38$ \\
\hline 20 & +1 & -1 & +1 & +1 & $30,34 \pm 0,47$ & +1 & -1 & +1 & +1 & $21,89 \pm 0,11$ \\
\hline 21 & +1 & +1 & -1 & -1 & $31,59 \pm 0,13$ & +1 & +1 & -1 & -1 & $51,98 \pm 0,30$ \\
\hline 22 & +1 & +1 & -1 & +1 & $26,27 \pm 0,32$ & +1 & +1 & -1 & +1 & $54,64 \pm 0,11$ \\
\hline 23 & +1 & +1 & +1 & -1 & $18,64 \pm 0,55$ & +1 & +1 & +1 & -1 & $46,40 \pm 0,83$ \\
\hline 24 & +1 & +1 & +1 & +1 & $21,65 \pm 0,38$ & +1 & +1 & +1 & +1 & $54,91 \pm 0,42$ \\
\hline
\end{tabular}

$\%$ de AR na farinha s/tratamento $10,62 \pm 0,65^{*}$

Exp.=experimento; $\mathrm{T}=$ temperatura; média e desvio padrão de 6 repetições; *apresentam diferença significativa entre elas, segundo teste de Tukey $(P<0,05)$.

e para uma farinha de arroz branca de referência citada por King e Tan. ${ }^{11}$ Verifica-se que a composição da farinha da de arroz crua foi muito semelhante à composição de referência, concordando com os valores descritos por Kulp e Ponte. ${ }^{20}$

\section{Massa específica aparente da farinha de arroz}

Os valores de $\rho_{\text {aparente }}$ encontrados para a farinha de arroz crua, farinha de arroz modificada pela lipase pancreática (amostra do experimento12) e amiloglicosidase (amostra do experimento 14) foram de $0,8725 \pm 0,007,0,7585 \pm 0,002$ e $0,6636 \pm 0,005 \mathrm{~kg} / \mathrm{m}^{3}$, respectivamente. As três amostras apresentaram diferença significativa entre elas, segundo teste de Tukey, sendo que a farinha hidrolisada pela amiloglicosidase apresentou uma diminuição na massa específica de $24 \%$ em relação à farinha crua. Segundo Sclowitz ${ }^{21} \mathrm{e}$ Cereda et al. ${ }^{22}$ a diminuição da massa específica de uma farinha de arroz extrusada é resultado da quebra das ligações químicas entre os componentes do amido, seguida de uma expansão, o que gera uma farinha com maior volume. Por outro lado, a farinha obtida por processo enzimático não apresentou ganho de volume, sugerindo que houve uma modificação na conformação molecular do amido e dos demais componentes da farinha, resultando numa farinha mais leve com o mesmo volume.

\section{Análise estatística}

A matriz proposta para cada enzima, juntamente com os resultados obtidos é mostrada na Tabela 3. 
Para a lipase pancreática, os valores mais elevados de amido resistente foram obtidos nas condições empregadas no experimento $12(\mathrm{E} / \mathrm{S}=4 \%, 2 \mathrm{~h}, \mathrm{pH} 7 \mathrm{e} \mathrm{Dp=100/200)}$, alcançando valores de $46,3 \%$, o que representa um aumento significativo $(P<0,05)$ de 4,3 vezes na quantidade de $\mathrm{AR}$ em relação à farinha sem tratamento.

Empregando-se a amiloglicosidase, a maior quantidade de AR foi obtida nas condições do experimento $14(\mathrm{E} / \mathrm{S}=0,006 \mathrm{mg} / \mathrm{mL}$, $\mathrm{T}=45{ }^{\circ} \mathrm{C}, 2 \mathrm{~h}$ e $\mathrm{Dp}=100 / 200$ ), alcançando valores próximos de $57 \%$, um aumento significativo de 5,3 vezes em relação à farinha sem tratamento.

A Figura 1 apresenta os efeitos estimados e sua significância na modificação enzimática da farinha de arroz.

A)

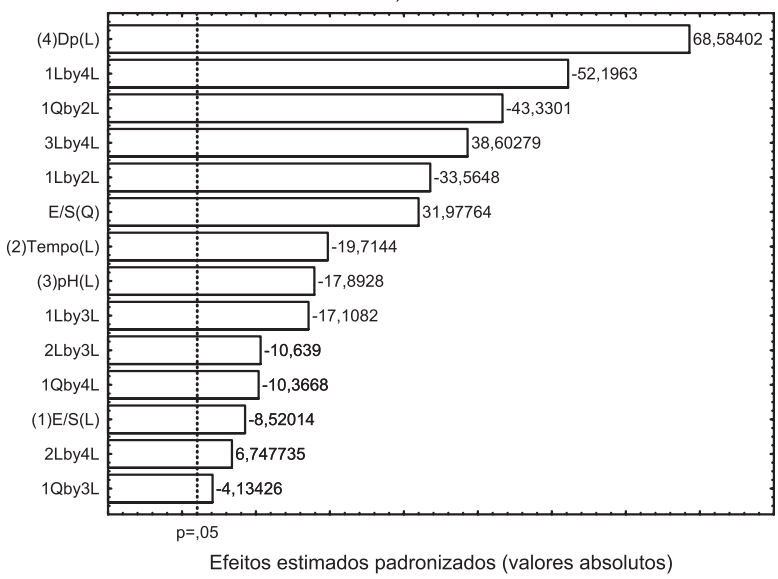

B)

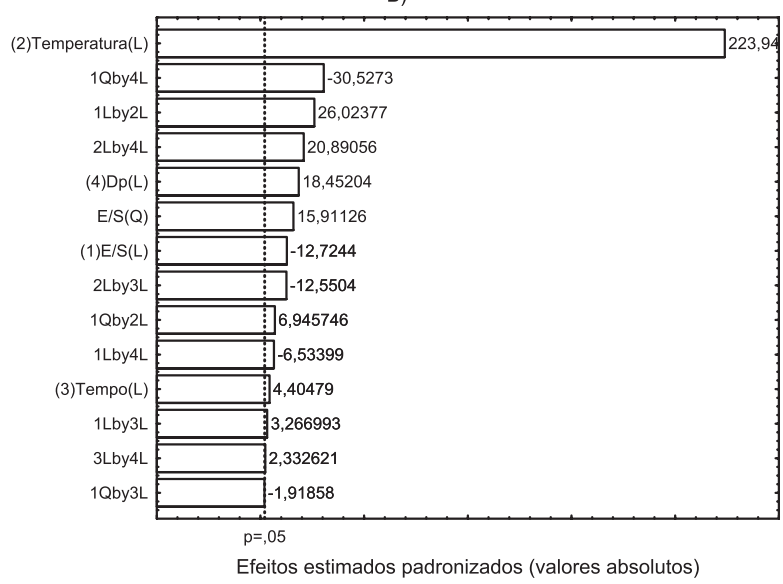

Figura 1. Efeitos estimados das variáveis sobre a produção de amido resistente através de modificação enzimática: a) com enzima lipase pancreática; b) com enzima amiloglicosidase

Os fatores que mais contribuíram significativamente $(P<0,05)$ no aumento da fração de AR, utilizando-se a enzima lipase pancreática (Figura 1a), foram o Dp, seguido da interação entre $\mathrm{pH}$ x Dp e relação E/S (Q). A interação entre E/S x Dp, assim como E/S x tempo influenciaram negativamente na produção de AR. Empregando-se a amiloglicosidase, a temperatura do processo (Figura 1b) foi o fator com maior influência no aumento da fração de AR, mostrando-se altamente significativo, seguido da interação temperatura x E/S, temperatura x Dp, E/S x Dp, Dp e E/S (Q). Considerando os efeitos significativos, os dados obtidos para porcentagem de amido resistente para cada enzima foram ajustados por análise de regressão múltipla para modelos quadráticos, conforme demonstrado pelas Equações 2 e 3.
$Y_{1}=31,46-0,66 X_{1}-4,32 X_{1}^{2}-5,16 X_{2}-1,51 X_{3}+3,44 X-2,62 b_{12} X_{1} X_{2}$ $+5,86 X_{1}^{2} X_{2}-1,33 X_{1} X_{3}+0,55 X_{1}^{2} X_{3}-4,07 X_{1} X_{4}+1,40 X_{1}^{2} X_{4}-0,67 X_{2} X_{3}$ $+0,43 X_{2} X_{4}+2,46 X_{3} X_{4}$

$Y_{2}=37,30-1,13 X_{1}-2,45 X_{1}^{2}-17,01 X_{2}-1,79 X_{4}-2,32 X_{1} X_{2}-1,07 X_{1}^{2} X_{2}$ $+0,29 X_{1} X_{3}-0,58 X_{1} X_{4}+4,71 X_{1}^{2} X_{4}-0,91 X_{2} X_{3}+1,52 X_{2} X_{4}+0,16 X_{3} X_{4}$

A validade dos modelos propostos foi verificada por meio de análise de variância (Tabela 4), na qual se constatou que as regressões obtidas foram estatisticamente significativas $(P<0,05)$, apresentando coeficientes de determinação $\left(R^{2}\right)$ de 0,81 para lipase pancreática e 0,98 para amiloglicosidase. Através dos testes $\mathrm{F}\left(\mathrm{F}_{\text {calc }} / \mathrm{F}_{\text {tab }}\right)$, verifica-se que os modelos construídos, para ambas as enzimas, foram significativos, ou seja, os dados preditos aproximam-se dos experimentais. Um modelo teórico pode ser considerado preditivo quando apresenta um valor $\mathrm{F}_{\text {calculado }}$ superior a pelo menos 3 vezes o valor de $\mathrm{F}_{\text {tabelado }}{ }^{14,23}$

Tabela 4. Análise de variância referente aos modelos aplicados para produção de amido resistente (AR) com lipase pancreática e amiloglicosidase

\begin{tabular}{lccccc}
\hline $\begin{array}{l}\text { Fontes de } \\
\text { Variação }\end{array}$ & SQ & GL & MQ & $\mathrm{F}_{\text {calculado }}$ & $\mathrm{F}_{\text {tabelado }}$ * \\
\hline Regressão & 2795,97 & 14 & 199,71 & 10,20 & 2,01 \\
Resíduo & 646,20 & 33 & 19,58 & - & - \\
Total & 3442,17 & 47 & - & - & $\mathrm{R}^{2}=0,81$ \\
& & \multicolumn{7}{c}{ Amiloglicosidase } \\
Regressão & 13539,65 & 14 & 967,11 & 177,12 & 2,01 \\
Resíduo & 180,18 & 33 & 5,46 & - & - \\
Total & 13719,83 & 47 & - & - & $\mathrm{R}^{2}=0,98$ \\
\hline
\end{tabular}

* Significância ao nível de $95 \%(P<0,05)$

A Figura 2 ilustra as superfícies de contorno, geradas pelo modelo apresentado na Equação 2, para produção de amido resistente empregando a enzima lipase pancreática. A Figura 2a apresenta a influência do Dp em função pH e a Figura 2b, a influência da relação Dp em função da relação E/S. Observa-se que as maiores quantidades de amido resistente foram alcançadas em concentrações de lipase pancreática intermediárias (E/S próximas de 4\%), maior Tyler, ou seja, menor diâmetro de partícula $(0,149 / 0,074 \mathrm{~mm})$, maior valor de $\mathrm{pH}(7,0)$ e menor tempo de reação $(2 \mathrm{~h})$. Nestas condições foram alcançados valores próximos de $41 \%$ (teórico) de AR, chegando próximos a $46 \%$ (experimental).

Ao diminuir o Dp de 0,707/0,297 mm (fração passante/fração retida) para 0,149/0,074 mm houve um aumento significativo na fração de AR. A farinha de arroz com menor granulometria, possuindo maior área de contato com a enzima, favorece a ação enzimática nas cadeias proteicas e amiláceas e aumenta, desta forma, o grau de hidrólise do amido, alterando, consequentemente, a digestibilidade da farinha. ${ }^{24}$ A lipase pancreática, por ser uma enzima impura contém outras hidrolases (como amilases e proteases), que podem ser benéficas ao tratamento atuando diretamente nas camadas externas do grânulo e hidrolisando os complexos lipídio-amilose e proteína-amilose e, com isso, chegando às regiões mais internas, frágeis e susceptíveis à hidrólise amilolítica. Entretanto, a hidrólise das camadas mais internas (amorfas) pela ação da lipase pancreática ocorre em menor intensidade quando comparada à ação da amiloglicosidase, o que pode explicar o fato desta farinha ter perdido menos massa (medida através da massa específica), em relação à ação com a amiloglico- 


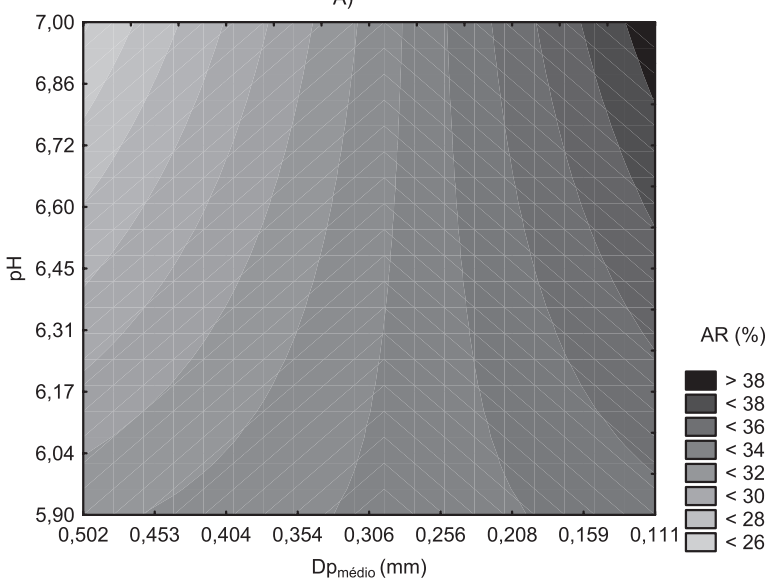

B)

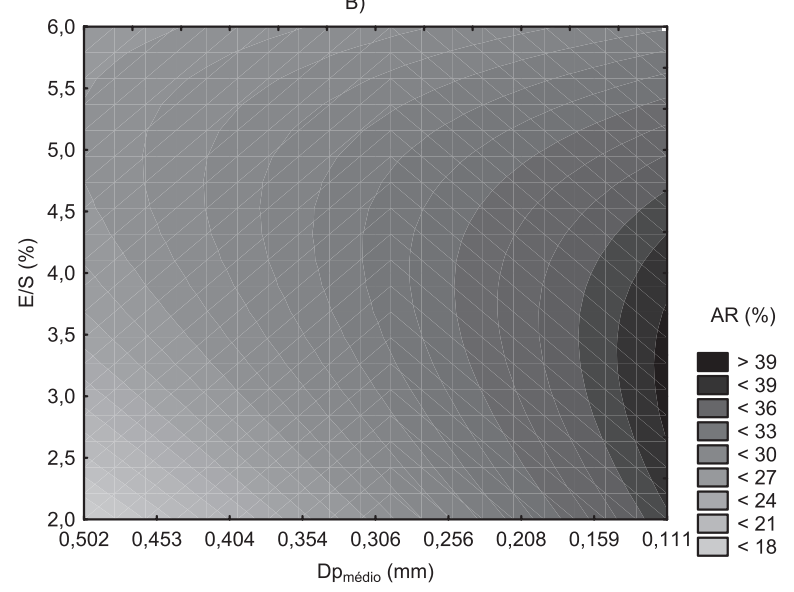

Figura 2. Superfícies de contorno da influência das variáveis sobre a produção de AR utilizando a enzima lipase pancreática: a) Dp em função do pH (mantendo constante Tempo -1 e E/S O); b) Dp em função da relação E/S (mantendo constante $\mathrm{pH}+1$ e Tempo -1). O D $p_{\text {médio }}$ foi obtido da média aritmética da fração passante e a fração retida nos respectivos níveis

sidase, tendo em vista que quanto menor a perda de massa menor a quebra de ligações entre as moléculas..$^{21,22}$

A Figura 3 ilustra as superfícies de contorno, geradas pelo modelo descrito na Equação 3, para obtenção de amido resistente com a enzima amiloglicosidase. A Figura 3a apresenta a influência da temperatura em função da relação E/S e a Figura 3b, a influência da temperatura em função do Dp. A observação das Figuras $3 a$ e $3 b$ indica que os valores mais elevados de $\mathrm{AR}$ foram alcançados em níveis mais elevados de temperatura $\left(45^{\circ} \mathrm{C}\right)$. Apesar das variáveis relação E/S e o Dp terem apresentados efeitos significativos, as influências desses fatores não foram tão pronunciados quanto o efeito da variável temperatura. Independente dos níveis das variáveis relação $\mathrm{E} / \mathrm{S}$ e Dp, se a temperatura for mantida a $45^{\circ} \mathrm{C}$ e o tempo em $2 \mathrm{~h}$, serão alcançados valores de AR superiores a $54 \%$, o que significa dizer que uma menor relação E/S implica em menores custos ao processo, e um maior $\mathrm{Dp}(0,707 / 0,297 \mathrm{~mm})$ resulta em maior rendimento de farinha.

A temperatura de $45^{\circ} \mathrm{C}$ favorece a ação da amiloglicosidase nas regiões amorfas da farinha..$^{25} \mathrm{O}$ aumento da temperatura para $45^{\circ} \mathrm{C}$, sem uma transformação profunda nos grânulos de farinha, a não ser um ligeiro intumescimento das regiões amorfas do grânulo, durante um tempo de 2 a $5 \mathrm{~h}$ pode ter gerado uma pré-modificação de annealing $^{26,27}$ e, justamente com esta condição aliada à ação da enzima, houve uma desorganização das cadeias de amido, principalmente nas regiões amorfas. Isto provavelmente pode ter causado a perda de massa
A)

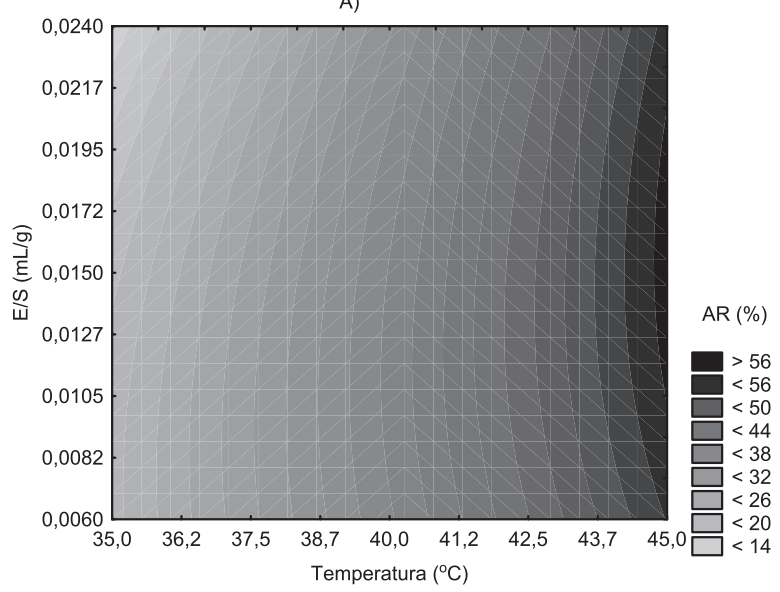

B)

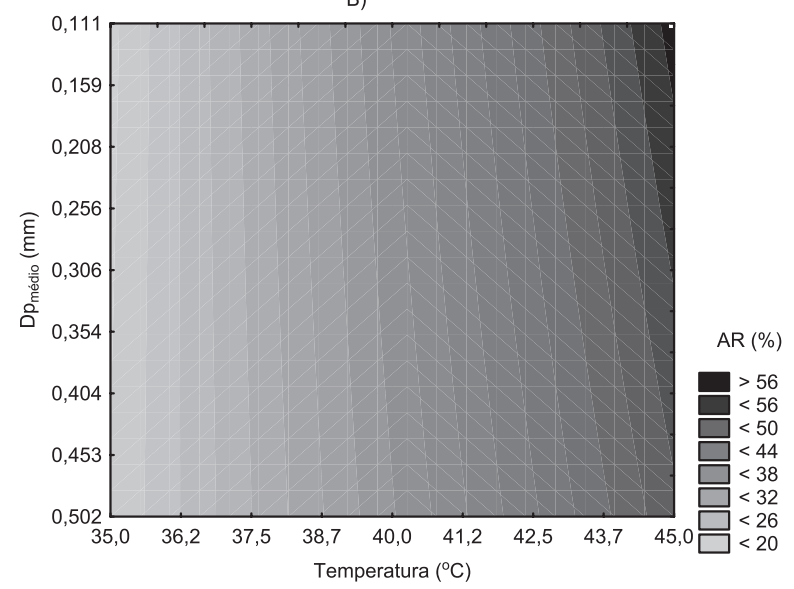

Figura 3. Superfícies de contorno da influência das variáveis sobre a produção de AR utilizando a enzima amiloglicosidase: a) temperatura em função da relação E/S (mantendo Tempo -1 e Dp +1 ); b) temperatura em função do $D p$ (mantendo E/S 0 e Tempo -1). O D ${ }_{\text {médio }}$ foi obtido da média aritmética da fração passante e a fração retida nos respectivos níveis

da farinha, com uma posterior reorganização desta região e aumento da resistência à hidrólise após as etapas de centrifugação e secagem. ${ }^{28}$ A rápida desorganização dessa região (amorfa) deve-se a menor organização da rede interior dos grânulos, o que reforça as indicações da existência de uma camada mais externa resistente à ação de amilases. ${ }^{25}$

Os valores obtidos no presente trabalho se comparam favoravelmente aos dados descritos na literatura. Guraya et al. ${ }^{29}$ verificaram o efeito da concentração da enzima pullulanase $(10 \% \mathrm{E} / \mathrm{S})$ e do tempo de hidrólise (4 h) na modificação enzimática de amido de arroz, encontrando valores próximos a $30 \%$ de AR. Chiu et al. ${ }^{12}$ avaliaram a produção de produtos amiláceos contendo pelo menos $15 \%$ de $\mathrm{AR}$ em amostras de amido com elevado conteúdo de amilose ( 40\%), em diferentes condições de secagem e cristalização com sal, e constataram que esta operação influenciou no conteúdo de AR do produto final, atingindo teores da ordem de 30-40\%. Estes autores realizaram uma gelatinização do amido anteriormente ao tratamento enzimático com pullulanase. Iyengar et al. ${ }^{30}$ desenvolveram um método para a produção de AR tipo III a partir de amido de mandioca com elevado conteúdo de amilose (HAMS), envolvendo um tratamento enzimático anterior ao cozimento $\left(60-120^{\circ} \mathrm{C}\right)$ e resfriamento $\left(4^{\circ} \mathrm{C}\right)$, obtendo um material predominantemente cristalino com $92 \%$ de resistência a $37^{\circ} \mathrm{C}$.

King e $\operatorname{Tan}^{11}$ avaliaram o efeito do tratamento enzimático da farinha de arroz e amido de arroz na produção de AR. Amostras de farinha de arroz gelatinizadas e não gelatinizadas foram tratadas com 
pullulanase, $\alpha$-amilase e pullulanase $+\alpha$-amilase, em diferentes tempos (2, 4 e 16 h). Para a farinha de arroz não gelatinizada, o melhor rendimento em $\mathrm{AR}(4,48 \%)$ foi alcançado pela ação da pullulanase em $4 \mathrm{~h}$ de tratamento. Para a farinha de arroz gelatinizada, o rendimento em AR foi da ordem de 13,6\% em 16 h de tratamento.

\section{CONCLUSÃO}

A hidrólise enzimática empregando tanto lipase pancreática e amiloglicosidase produziu um aumento significativo no conteúdo de amido resistente da amostra farinha de arroz (Amitec 100), atingindo 5,36 vezes de acréscimo. A análise de variância mostrou que os ajustes dos modelos propostos para determinar a produção de AR através da modificação enzimática da farinha de arroz, para ambas as enzimas em função dos parâmetros estudados, foram preditivos. O fator que mais influenciou significativamente no incremento da fração de AR, utilizando-se a enzima lipase pancreática, foi o Dp, no qual o aumento no Tyler, ou seja, diminuição do tamanho da partícula $(0,149 / 0,074$ $\mathrm{mm}$ ), mantendo-se a relação E/S em 4\%, tempo de hidrólise de $2 \mathrm{~h}$ e o pH em 7,0, fez com que os níveis de AR alcançassem $46 \%$. O fator que mais contribuiu significativamente para o aumento da fração de AR, utilizando-se a enzima amiloglicosidase, foi a temperatura $\left(45^{\circ} \mathrm{C}\right)$, na qual o aumento da temperatura, mantendo-se a relação E/S em $0,015 \mathrm{~mL} / \mathrm{g}$, tempo de hidrólise de $2 \mathrm{~h}$, e menor Dp $(0,149 / 0,074$ $\mathrm{mm})$, resultou em níveis de AR da ordem de 57\%. A comparação do desempenho das enzimas testadas indica que a ação da amiloglicosidase foi $24 \%$ superior à atuação da lipase pancreática. Entretanto, uma comparação de custos deve ser ainda efetuada para permitir a seleção da preparação que ofereça melhor custo benefício.

\section{REFERÊNCIAS}

1. Lobo, A. R.; Lemos Silva, G. M.; Rev. Nutr. 2003, 16, 219.

2. Pereira, K. D.; Ciênc. Tecnol. Aliment. 2007, 27, 88.

3. Borges, J. T. S.; Ascheri, J. L. R.; Ascheri. D. R.; Nascimento, R. E.; Freitas, A. S.; B. CEPPA 2003, 21, 303.

4. http://www.ibge.gov.br/home/estatistica/indicadores/agropecuaria/lspa/ 1spa_200901_5.shtm, acessada em Março 2009.

5. Severo, M. G.; Dissertação de Mestrado, Universidade Federal do Rio Grande, Brasil, 2005.

6. Englyst, H. N.; Cummings, J. H.; Am. J. Clin. Nutr. 1987, 45, 423.

7. Sajilata, M. G.; Singhal, R. S.; Kulkarni, P. R.; Comp. Rev. Food Sci. Food Saf. 2006, 5, 1.
8. Englyst, K. N.; Liu, S.; Englyst, H. N.; Eur. J. Clin. Nutr. 2007, 61, 19.

9. Haralampu, S. G.; Carbohydr. Polym. 2000, 41, 285.

10. Beninca, C.; Demiate, I. M.; Lacerda, L. G.; Carvalho Filho, M. A. S.; Ionashiro, M.; Schnitzler, E.; Ecl. Quím. 2008, 33, 13; Chiu, C. W.; US pat.4,971,723, 1990; Chiu, C. W.; Henley, M.; Altieri, P.; US pat. 5,281,276, 1994; Henley, M.; Chiu, C. W.; US pat. 5,409,542, 1995; Kettlitz, B. W.; Coppin, J. V. J.; Roper, H. W. W.; Bornet, F.; US pat. 6,043,229, 2000.

11. King, J. M.; Tan, S. Y.; US App. $20050089624,2005$.

12. Chiu, C. W.; Henley, M.; Altieri, P.; CA pat 2092009, 1993.

13. Barros Neto, B.; Scarminio, I. S.; Bruns, R. E.; Planejamento e otimização de experimentos, $2^{\mathrm{a}} \mathrm{ed}$., Ed. da Unicamp: Campinas, 1996.

14. Rodrigues, M. I,; Iemma, A. F.; Planejamento de experimentos $e$ otimização de processos: Uma estratégia seqüencial de planejamentos, 5a ed., Casa do Pão Ed.: Campinas, 2005.

15. Official Methods of Analysis of the AOAC, $17^{\text {th }}$ ed., Arlington: USA, 2000.

16. Bligh, E. G.; Dyer, W. J.; Can. J. Biochem. Physiol. 1959, 37, 911.

17. Sowbhagya, C. M.; Bhattacharya, K. R.; Starch 1979, 31, 159.

18. Englyst, H. N.; Kingman, S. M.; Cummings, J. H.; Eur. J. Clin. Nutr. 1992, 46, 33 .

19. Woo, K. S.; Seib, P. A.; Cereal Chem. 2002, 79, 819.

20. Kulp, K.; Ponte, J. G.; Handbook of cereal science and technology, $2^{\text {nd }}$, CRC: New York, 2000.

21. Sclowitz, L. F.; Dissertação de Mestrado, Universidade Federal do Rio Grande, Brasil, 2003.

22. Cereda, M. P.; Vilpoux, O.; Demiate, I. M. Em Tecnologia, usos e potencialidades de tuberosas amiláceas latino americanas, 2003, vol. 3, cap. 12.

23. Biazus, J. P. M.; Souza, R. R.; Curvelo-Santana, J. C.; Tambourgi, E. B.; Ciênc. Tecnol. Aliment. 2006, 26, 787.

24. Manelius, R.; Nurmi, K.; Bertoft, E.; Cereal Chem. 2000, 77, 345.

25. Surmely, R.; Alvarez, H.; Cereda, M. P.; Velpoux, O. F. Em ref. 22, cap. 15.

26. Hoover, R.; Zhou, Y.; Carbohydr. Polym. 2003, 54, 401.

27. Tharanathan, R. N.; Crit. Rev. Food. Sci. Nutr. 2005, 45, 371.

28. Tribess, T. B.; Hernández-Uribe, J. P.; Méndez-Montealvo, M. G. C.; Menezes, E. W.; Bello-Perez, L. A.; Tadini, C. C.; LWT - Food Sci. Technol. 2009, 42, 1022.

29. Guraya, H. S.; James, C.; Champagne, E. L.; Starch 2001, 53, 131.

30. Iyengar, R.; Zaks, A.; Gross, A.; US pat.5,051,271, 1991. 